\title{
Hesperedin promotes
}

MyoD-induced myogenic differentiation in vitro and

Hana Jeong ${ }^{1}$, Joo Yeon Lee ${ }^{1}$, Eun Jung Jang ${ }^{1}$, Eun Hye Lee ${ }^{1}$, Myung Ae Bae ${ }^{2}$, Jeong-Ho Hong ${ }^{3}$ and Eun Sook Hwang ${ }^{1}$

${ }^{1}$ College of Pharmacy and Division of Life and Pharmaceutical Sciences and Center for Cell Signaling \& Drug Discovery Research, Ewha Womans University, Seoul, Korea, ${ }^{2}$ Korea Research Institute of Chemical Technology, Daejeon, Korea, and ${ }^{3}$ School of Life Science and Biotechnology, Korea University, Seoul, Korea

\section{Correspondence}

Eun Sook Hwang, College of Pharmacy and Division of Life and Pharmaceutical Sciences, Ewha Womans University, 11-1 Daehyun-Dong, Seodaemun-Ku, Seoul 120-750, Korea. E-mail: eshwang@ewha.ac.kr Jeong-Ho Hong, School of Life Science and Biotechnology, Korea University, Seoul 136-701, Korea. E-mail: jh_hong@Korea.ac.kr

\section{Keywords}

hesperedin; myogenic

differentiation; MyoD; myogenin; MCK

\section{Received}

4 September 2010

Revised

30 November 2010

Accepted

21 December 2010

\section{BACKGROUND AND PURPOSE}

The bioflavonoid, hesperedin, promotes osteoblast differentiation in human mesenchymal stem cells, indicating an anabolic effect of hesperedin on bone metabolism. Murine bone marrow mesenchymal stem cells undergo myogenic differentiation as well as osteogenic differentiation. We therefore explored whether hesperedin modulates muscle cell differentiation.

\section{EXPERIMENTAL APPROACH}

Myoblast $\mathrm{C} 2 \mathrm{C} 12$ cells were differentiated into muscle cells in the presence or absence of hesperedin. The effects of hesperedin on myogenic differentiation were determined by analysing specific muscle markers in vitro using reporter gene assays, immunoblotting, RT-PCR and DNA pull-down assays. In vivo, the effects of hesperedin were assessed using the freeze injury-induced muscle regeneration model in mice and daily injections of hesperedin for 6 days.

\section{KEY RESULTS}

Hesperedin promoted myogenic differentiation, in a dose-dependent manner, by increasing myogenin gene expression. MyoD-induced myogenin gene transcription was enhanced by hesperedin, as this bioflavonoid augmented the nuclear localization and myogenin promoter-binding of MyoD. In addition, hesperedin increased myogenin and muscle creatine kinase gene expression during myogenic differentiation from $\mathrm{C} 3 \mathrm{H} 10 \mathrm{~T} 1 / 2$ mesenchymal stem cells in a MyoD-dependent manner and accelerated in vivo muscle regeneration induced by muscle injury.

\section{CONCLUSIONS AND IMPLICATIONS}

Our results demonstrate that hesperedin promoted myogenic differentiation in vitro and in vivo through activation of MyoD-mediated myogenin expression, suggesting a beneficial role in promoting muscle regeneration, following injury.

\section{Abbreviations}

MCK, muscle creatine kinase; MEF, myocyte enhancer factor; MHC, myosin heavy chain; DAPI, 4',6-diamidino-2-phenylindole

\section{Introduction}

Many bioflavonoids have been identified and exhibit biological activities such as antioxidant, antibacterial and antiinflammatory properties (Huang et al., 2005; Amin et al., 2007; Cazarolli et al., 2008; Viuda-Martos et al., 2008). Hes- peridin and its aglycone hesperedin are classified as citrus bioflavonoids and exert anti-atherogenic activity by reducing apolipoprotein B secretion (Borradaile et al., 1999; Wilcox et al., 2001) and by suppressing the gene expression of microsomal triglyceride transfer protein and acyl CoA: cholesterol acyltransferase (ACAT) 2 (Wilcox et al., 2001; 
Borradaile et al., 2003). Orally administered hesperedin is converted to a de-glycosylated metabolite, hesperedin, by intestinal microflora in vivo. This aglycone suppresses histamine release from mast cells, exhibiting an anti-allergic activity (Ameer et al., 1996; Lee et al., 2004). In addition, hesperedin protects neuronal cells and osteoblasts from oxidative stress by functioning as a potent radical scavenger (Kim et al., 2004; Hirata et al., 2005; Cho, 2006; Choi and Kim, 2008) and suppresses proliferation of breast cancer cells by arresting the cell cycle at the G1 phase (Choi, 2007). More recently, hesperedin was reported to enhance osteoblast differentiation by increasing alkaline phosphatase activity and by inducing RUNX2 activation in the bone morphogenetic protein signalling pathway, suggesting an anabolic effect of hesperedin on bone metabolism (Trzeciakiewicz et al., 2010a,b)

Mesenchymal stem cells in adult bone marrow are multipotent stem cells that can differentiate into osteoblasts, adipocytes, chondrocytes and myocytes (Harada et al., 2003; Gregory et al., 2005). Cell lineage commitment is accompanied by the activation of lineage-specific transcription factors such as RUNX2 (Komori et al., 1997), peroxisome proliferation-activated receptor (PPAR) $\gamma$ (Tontonoz et al., 1994), SOX9 (Bi et al., 1999) and MyoD (Davis et al., 1987). In particular, myocyte differentiation is regulated by various muscle regulatory factors (MRFs), including MyoD, Myf5, myogenin and MRF4 (Rudnicki et al., 1993). MyoD initiates the expression of muscle-specific genes and induces commitment of mesenchymal stem cells to the myogenic lineage (Berkes et al., 2005). Induction of myogenin expression is controlled by MyoD activity and is crucial for terminal differentiation (Hasty et al., 1993; Nabeshima et al., 1993) and induction of muscle-specific genes like myosin heavy chain (MHC) and muscle creatine kinase (MCK) (Charge et al., 2004). Members of the myocyte enhancer factor 2 (MEF2) family of transcription factors are also able to modulate muscle differentiation, via cooperative association with myogenic transcription factors of the bHLH family, such as MyoD and myogenin (Molkentin et al., 1996).

In this study, we have investigated the effects of hesperedin on myogenic differentiation. We found that this bioflavonoid increased myogenic differentiation and muscle gene expression by promoting nuclear localization of MyoD and its DNA binding activity to the myogenin gene promoter. Furthermore, injury-induced muscle regeneration in mice was accelerated by treatment with hesperedin in vivo.

\section{Methods}

\section{Cell culture and differentiation}

Myoblast $\mathrm{C} 2 \mathrm{C} 12$ cells were maintained in DMEM supplemented with $10 \%$ fetal bovine serum (FBS). For myogenic differentiation, the cells were grown to confluence for $48 \mathrm{~h}$ and then induced to differentiate by replacing the growth medium with DMEM containing $2 \%$ horse serum every other day (Yaffe and Saxel, 1977). C3H10T1/2 mesenchymal stem cells and HEK 293T cells were maintained in DMEM supplemented with $10 \%$ FBS.

\section{Reporter gene assay}

C2C12 cells were transfected with MyoD or MEF2C expression vectors and the reporter genes, such as myogenin promoter-linked (pMyogenin-luc) and MCK promoter-linked luciferase gene (pMCK-luc), by calcium phosphate transfection (Jung et al., 2009). Three independent experiments were conducted and luciferase activity was assayed according to the manufacturer's instructions (Promega, Madison, WI, USA). A relative luciferase unit was determined by normalization to the $\beta$-galactosidase activity of pCMV $\beta$ (Clontech, Palo Alto, CA, USA), which was co-transfected as an internal control for transfection efficiency.

\section{Immunoblot analysis}

Whole cell extracts were prepared from the cells and resolved by sodium dodecyl sulphate (SDS)-polyacrylamide gel electrophoresis (7.5\% PAGE), followed by electrophoretic transfer to Immobilon-P membranes (Millipore Inc., Invitrogen). The blots were incubated with antibodies against myogenin, MyoD, MHC and $\beta$-actin (1:1000, Santa Cruz Biotech. Inc., Santa Cruz, CA, USA) and subsequently with secondary antibody (1:10 000, Zymed), followed by development using a luminal reagent (GE Healthcare, Buckinghamshire, UK).

\section{Immunofluorescence analysis}

$\mathrm{C} 2 \mathrm{C} 12$ cells were differentiated in the absence or presence of hesperedin and harvested at the indicated time points. Cells were permeabilized with $2 \%$ paraformaldehyde containing $0.1 \%$ Triton X-100, and were subjected to staining with myogenin or MHC antibody (1:100) and subsequent incubation with Alexa Fluor 488-conjugated secondary antibody (1:5000) (Jeong et al., 2010). Immunofluorescence was observed under a Zeiss Axiovert 200 fluorescence microscope (Carl Zeiss, Göttingen, Germany).

\section{Reverse transcription and real-time PCR analysis}

Total RNA was isolated from cultured cells using TRIzol reagent (Invitrogen) and subjected to reverse transcription for cDNA synthesis. Real-time PCR was performed using SYBR Green PCR mix (2X) and an ABI-Prism 7000 sequence detector (Applied Biosystems, San Mateo, CA, USA). The relative expression level of each mRNA was determined by the threshold cycle $(\mathrm{Ct})$ values after normalization to the level of $\beta$-actin. Real-time PCR was performed with specific primers $(0.3 \mu \mathrm{M})$ : $\beta$-actin-FWD 5 '-agagggaaatcgtgcgtgac-3', $\beta$-actinREV 5'-caatagtgatgacctggccgt-3'; MCK-FWD 5'-cacctccacagc acagacag-3', MCK-REV 5'-accttggccatgtgattgtt-3'; myogeninFWD 5'-caaccaggaggagcgagacctccg- $3^{\prime}$, myogenin-REV 5'-agg cgctgtgggatatgcattcact-3'; MyoD-FWD 5'-tgggatatggagcttctat cgc-3', MyoD-REV 5'-ggtgagtcgaaacacggatcat-3'.

\section{Chemiluminescent EMSA and DNA pull-down assay}

Nuclear proteins were prepared and incubated with biotinylated double-stranded myogenin promoter containing the MyoD-binding site according to the manufacturer's instructions (Active Motif Inc., Carlsbad, CA, USA). Briefly, reaction mixtures were resolved by non-denaturing PAGE and trans- 
A<smiles>COc1ccc([C@H]2CC(=O)c3c(O)cc(O)cc3O2)cc1O</smiles>

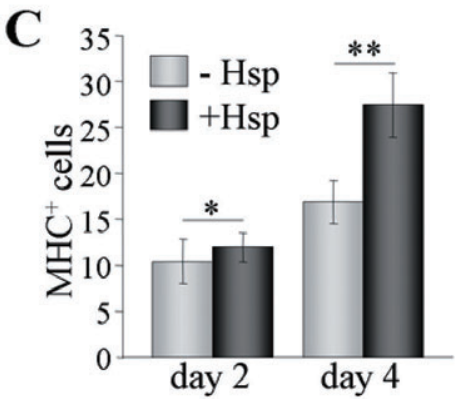

F

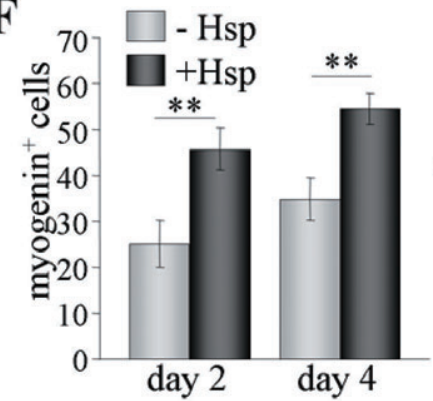

B

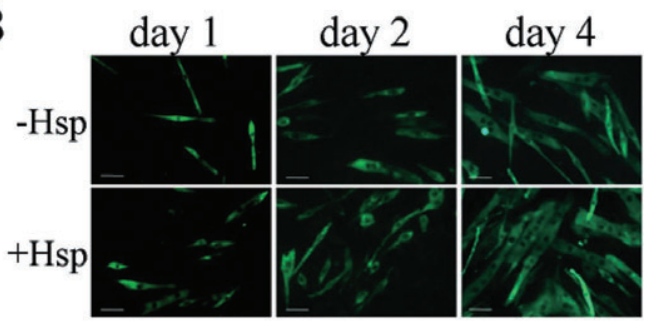

D
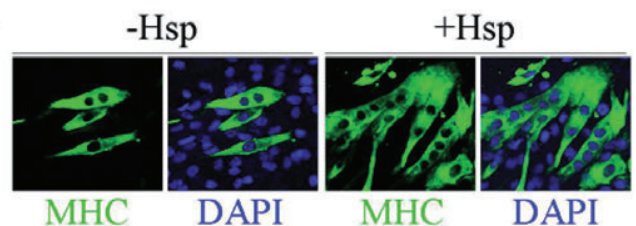

E

MHC
$\mathrm{MHC}$

DAPI

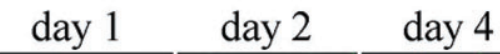

Hsp
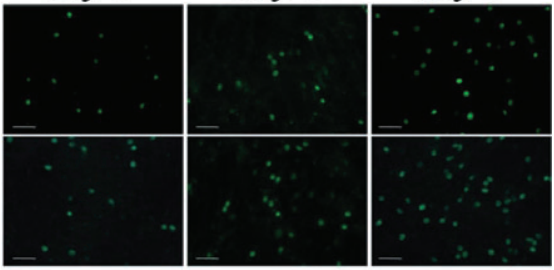

G

$+\mathrm{Hsp}$

-Hsp

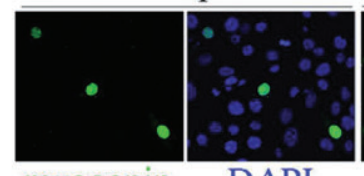

myogenin

DAPI

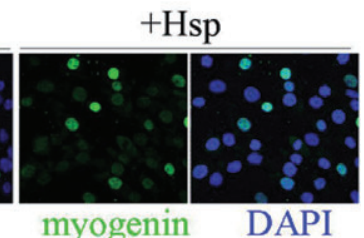

\section{Figure 1}

Enhanced myogenic differentiation by hesperedin. (A) Chemical structure of hesperedin. (B) Confluent C2C12 cells were induced to differentiate by replacing with DMEM supplemented with $2 \% \mathrm{HS}$ with either vehicle $(-\mathrm{Hsp})$ or hesperedin $(+\mathrm{Hsp}, 100 \mu \mathrm{M})$. Cells were fixed at the indicated differentiation time points and incubated with anti-MHC antibody, followed by incubation with Alexa Fluor 488-conjugated secondary antibody. (C) Fluorescence-positive cells as in Figure 1B were counted per field under a fluorescence microscope. The average and standard errors from 10 fields were calculated. (D) Cells were stained with anti-MHC antibody and subsequent Alexa Fluor 488-conjugated secondary antibody at differentiation day 4. The nuclei were stained with DAPI. (E) C2C12 cells during myogenic differentiation were incubated with anti-myogenin antibody and subsequent fluorescence-tagged secondary antibody. Cells were observed under low power magnification. (F) Myogenin-positive cells in Figure 1E were counted from 10 fields as described in Figure 1C. (G) Cells were differentiated for 4 days in the presence or absence of hesperedin $(100 \mu \mathrm{M})$ and stained with anti-myogenin antibody as well as DAPI for nuclear staining. Scale bars in Figure 1B, D and E indicate $50 \mu \mathrm{m} .{ }^{*} P<0.05 ;{ }^{* *} P<0.005$.

ferred to nylon membranes. The blot was incubated with streptavidin-horseradish peroxidase and subjected to chemiluminescent enhanced chemiluminescence. For DNA pulldown assay, cells were lysed using HKMG buffer $(10 \mathrm{mM}$ HEPES, pH 7.9, $100 \mathrm{mM} \mathrm{KCl,} 5 \mathrm{mM} \mathrm{MgCl2,} \mathrm{10 \%} \mathrm{glycerol,}$ $0.1 \% \mathrm{NP}-40,1 \mathrm{mM}$ dithiothreitol and protease inhibitor cocktail) and whole cell extracts were incubated with biotinylated myogenin promoter DNA, then incubated with streptavidin agarose beads. Precipitates were washed with HKMG buffer three times and analysed by SDS-PAGE and immunoblot assay using MyoD antibody.

\section{Myogenic conversion assay}

Phoenix cells were transfected with a retroviral vector that expresses MyoD using the standard calcium phosphate transfection method. Cells were then refreshed and transferred to a $32^{\circ} \mathrm{C}$ incubator for an additional $30 \mathrm{~h}$. The viral supernatant was added to C3H10T1/2 cells with polybrene $\left(8 \mu \mathrm{g} \cdot \mathrm{mL}^{-1}\right)$ for $48 \mathrm{~h}$. Cells were selected in the presence of puromycin $\left(2 \mu \mathrm{g} \cdot \mathrm{mL}^{-1}\right)$ and then induced to myogenic differentiation in the presence or absence of hesperedin.

\section{Injury-induced muscle regeneration and histological analysis}

All animal care and experimental procedures were approved by the Ewha Womans University Institutional Animal Care and Use Committee. C57BL/6 mice were purchased from the Jackson Laboratories (Bar Harbor, ME, USA) and housed in the Ewha Laboratory Animal Genomic Center under specific pathogen-free conditions and under the standard light/dark cycle. The model of muscle injury-induced regeneration following freeze injury described by Jeong et al. (2010) was used. 

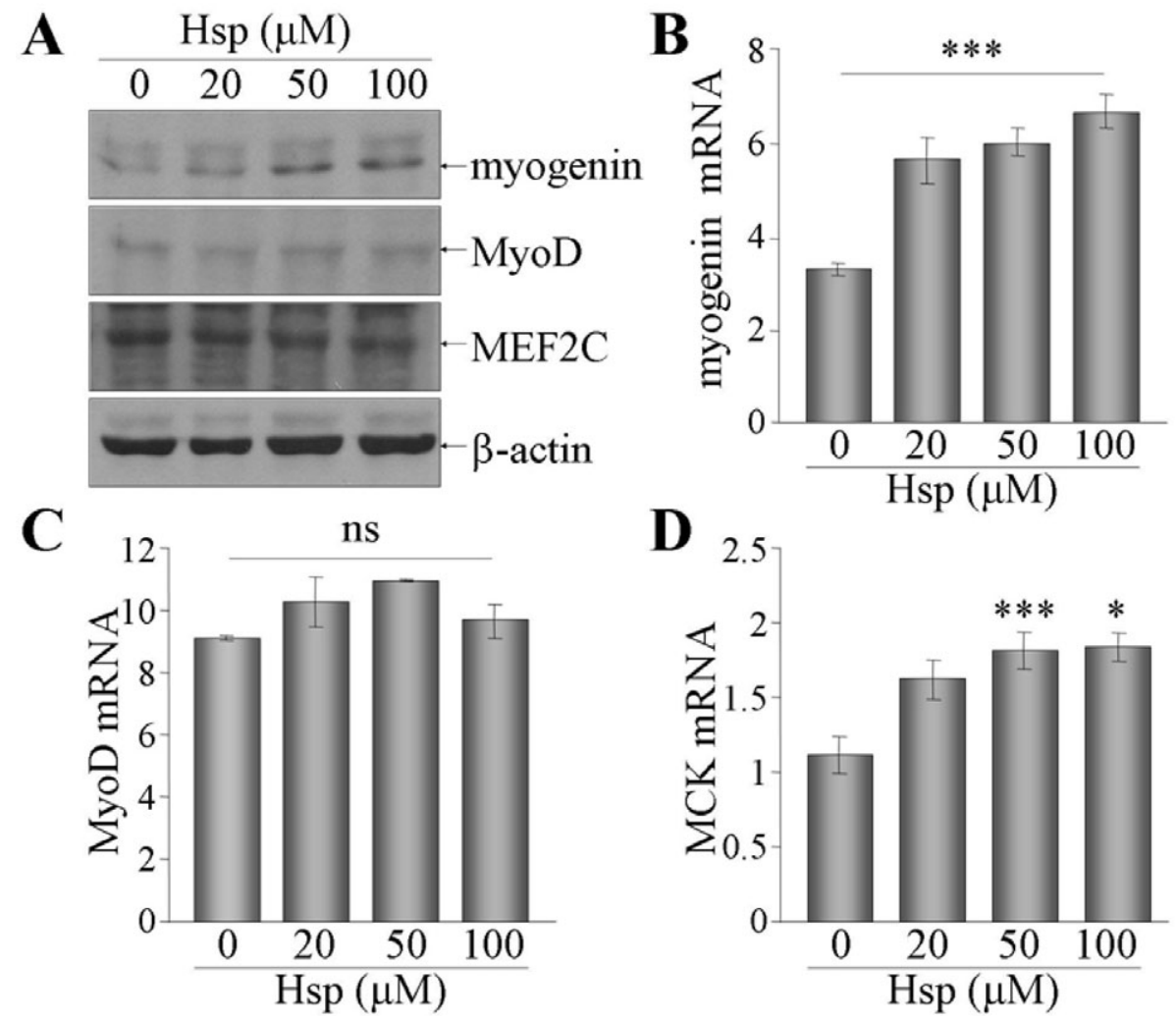

\section{Figure 2}

Augmentation of myogenin expression by hesperedin in myocytes. C2C12 cells were differentiated for 2 days in the presence of different concentrations of hesperedin ( $\mathrm{Hsp}$ ). (A) Whole cell extracts were resolved by SDS-PAGE and then, subjected to immunoblot assay using antibodies against MyoD, myogenin, MEF2C and $\beta$-actin. (B-D) Total RNA was harvested and subjected to reverse transcription and real-time PCR analysis. Relative expression of myogenin (B), MyoD (C) and MCK (D) was determined after normalization to $\beta$-actin levels. Data are given as means \pm SEM of three independent experiments. ns, not significant; ${ }^{*} P<0.05 ;{ }^{* * *} P<0.0005$.

Briefly, C57BL/6 mice were subjected to freeze injury in the tibialis anterior (TA) muscles and subsequently injected with either PBS or hesperedin every day for 6 days. On day 7 after injury, mice were killed for the preparation of protein extracts and tissue sections. TA muscles were isolated and $7 \mu \mathrm{m}$ sections prepared by microtome. Tissue sections were then stained with haematoxylin and eosin (Sigma-Aldrich, St. Louis, MO, USA).

\section{Statistical analysis}

All data are given as the means \pm SEM. Statistical significance was determined by unpaired Student's $t$-test or one-way ANOva. $P$-values less than 0.05 were considered statistically significant.

\section{Materials}

Hesperedin (purity 95\%) was obtained from Sigma-Aldrich. All reagents for cell culture were purchased from Gibco-BRL (Invitrogen), and FBS and horse serum were from HyClone (Logan, UT, USA).

\section{Results}

\section{Hesperedin promotes myogenic cell differentiation}

To investigate the effect of hesperedin in myogenic differentiation, myoblast C2C12 cells (Lassar et al., 1994) were induced to differentiate into myocytes in low mitogen medium in the absence or presence of hesperedin (Figure 1A). The morphological changes indicative of cylinder-shaped myocytes were time-dependently increased during myogenic differentiation (Figure 1B). Hesperedin significantly enhanced the numbers of cylinder-shaped myocytes and MHC expression, as shown by immunofluorescence staining using anti-MHC antibodies (Figure 1B and C). In addition, multinucleated myotubes, which are formed by cell fusion of terminally differentiated myocytes, were prominently observed among hesperedin-treated cells (Figure 1D). Myogenin expression was also considerably augmented in the presence of hesperedin during differentiation (Figure 1E and F). Myogenin expression was prominent in the nucleus (Figure 1G), indicating that hesperedin promotes myogenic gene expression and terminal differentiation. 

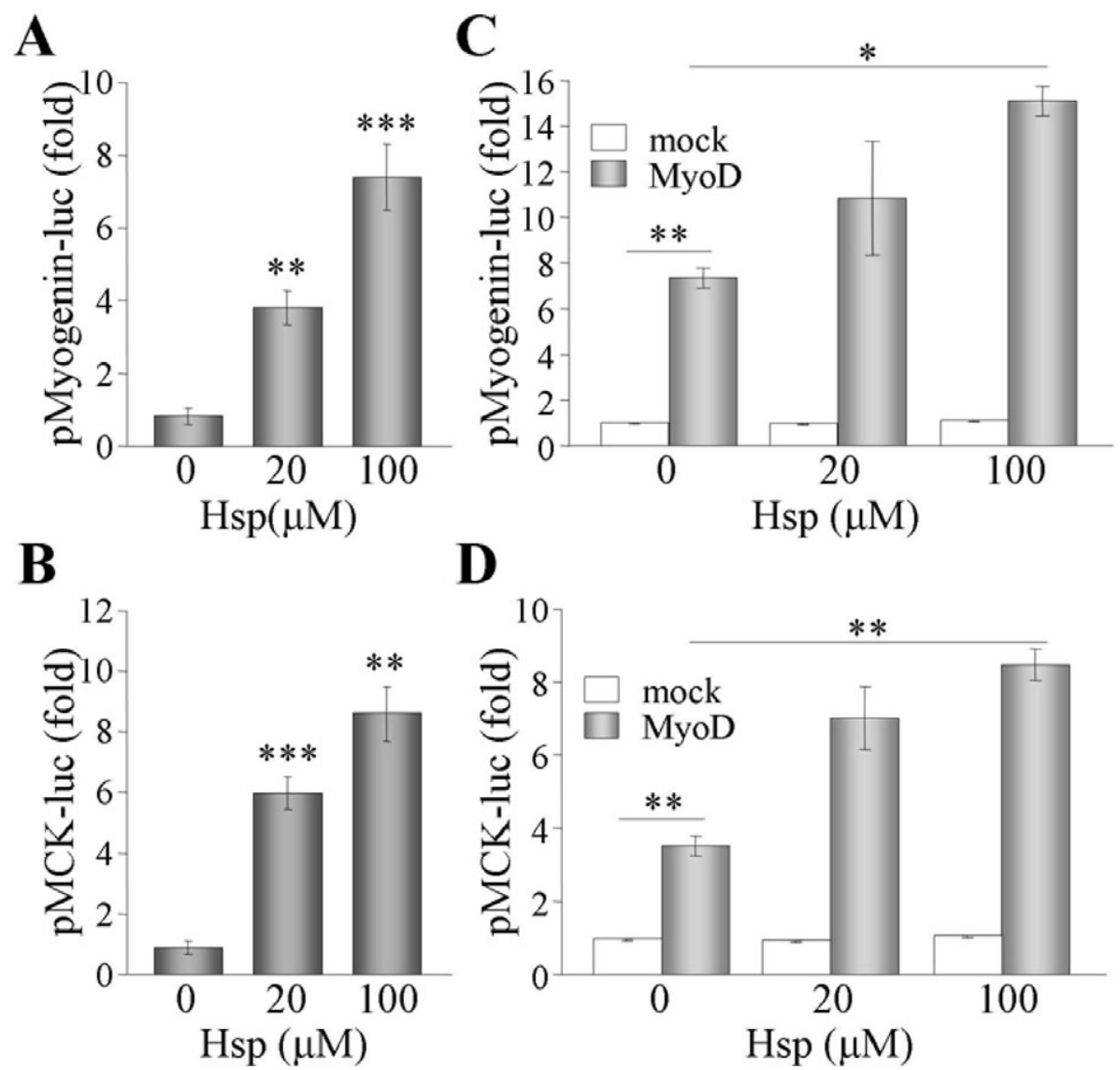

D

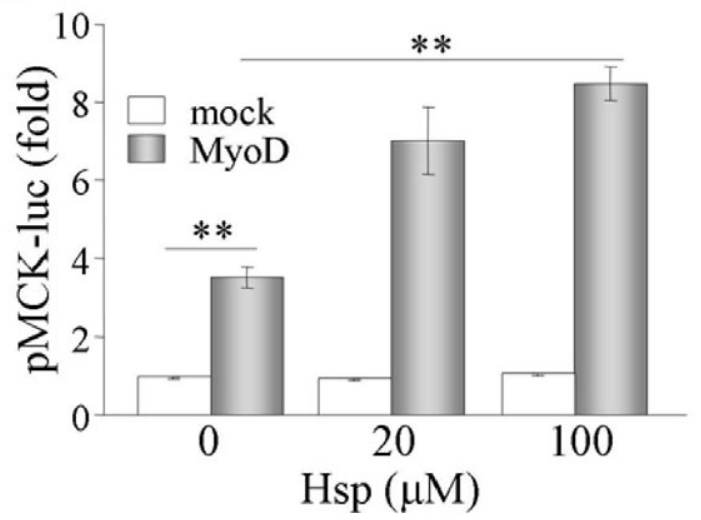

\section{Figure 3}

Modulation of myogenin and MCK gene transcription. (A-B) C2C12 cells were cultured to 50-60\% confluence in complete DMEM and transiently transfected with the pMyogenin-luc (A) or pMCK-luc (B) reporter gene as well as pCMV $\beta$. After $24 \mathrm{~h}$, cells were fed low mitogen medium and additionally incubated with hesperedin (Hsp) for $24 \mathrm{~h}$. (C-D) 293T cells were transfected with or without a MyoD expression vector together with either pMyogenin-luc (C) or pMCK-luc (D) reporter gene. Cells were incubated with hesperedin for an additional 24 h. Relative luciferase activity was determined by normalizing to $\beta$-galactosidase activity of control vector, $\mathrm{pCMV} \beta$. Fold induction was calculated by setting the control activity as 1 and data are given as means \pm SEM. ${ }^{*} P<0.05 ;{ }^{* *} P<0.005 ;{ }^{* * *} P<0.0005$.

\section{Myogenin gene transcription is promoted by hesperedin}

Because myogenic differentiation was promoted by hesperedin, we next examined the regulatory mechanisms of this bioflavonoid in myogenic gene expression. The expression levels of early MRFs were determined on differentiation day 2. The expression levels of MyoD and MEF2C were not changed by hesperedin, whereas it dose-dependently increased myogenin expression on day 2 (Figure 2A). Quantitative real-time PCR confirmed that hesperedin induced myogenin expression at the level of gene transcription, but did not affect MyoD gene transcription (Figure $2 \mathrm{~B}$ and $\mathrm{C}$ ). Hesperedin also boosted expression of the muscle-specific marker, MCK (Figure 2D). These results suggest that hesperedin may selectively control gene transcription of myogenin and MCK.

\section{Hesperedin enhances MyoD activity to induce gene transcription of myogenin and MCK Increased mRNA levels of myogenin and MCK by hespere- din provoked us to examine the regulatory functions of hes-}

peredin in gene transcription. In order to test whether hesperedin directly modulates gene transcription of myogenin and MCK, C2C12 cells were transfected with a luciferase reporter gene linked to a myogenin promoter (pMyogeninluc) or a MCK promoter (pMCK-luc) and were cultured in low mitogen medium with hesperedin for $24 \mathrm{~h}$. hesperedin substantially induced both myogenin and MCK promoter activity (Figure $3 \mathrm{~A}$ and $\mathrm{B}$ ), indicating that hesperedin may increase gene transcription of myogenin and MCK through promoter activation. Because both myogenin and MCK promoters possess myogenic bHLH protein binding sites, we tested whether a myogenic bHLH protein, MyoD, could be activated by hesperedin (Wilson and Rotwein, 2006). Ectopic expression of MyoD in 293T cells increased myogenin and MCK promoter activity by 7- and 4-fold respectively (Figure 3C and D). Hesperedin further increased these MyoD-induced gene promoter activities, but had no stimulatory effect in the absence of MyoD (Figure 3C and D). These results suggest that hesperedin may enhance the transcriptional activity of MyoD and induce its target gene transcription. 

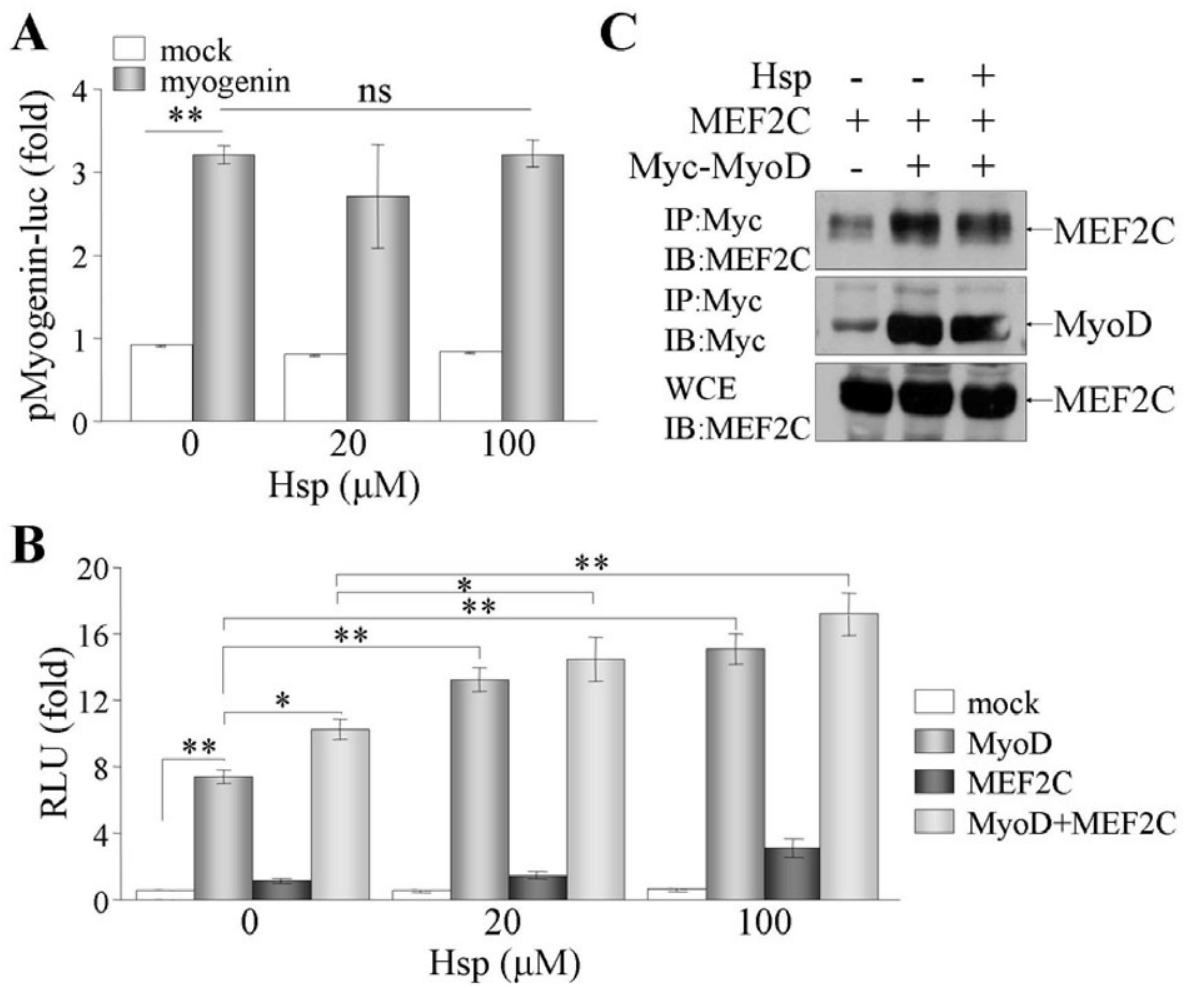

\section{Figure 4}

Specific function of hesperedin in MyoD activation. (A) 293T cells were transfected with a myogenin expression vector and pMyogenin-luc reporter gene. Reporter gene activity was determined from the normalized relative luciferase activity of three independent experiments. (B) The expression vectors, MyoD and MEF2C were transfected into 293T cells with pMyogenin-luc vector. Cells were incubated with hesperedin (Hsp) for $24 \mathrm{~h}$ and harvested for the reporter gene assay. Fold induction was calculated by taking the control activity (mock) as 1 and are expressed as means \pm SEM of three independent experiments. ns, not significant; ${ }^{*} P<0.05$; ${ }^{* *} P<0.005$. (C) 293T cells were co-transfected with Myc-tagged MyoD and/or MEF2C expression vectors and treated with hesperedin (100 $\mu \mathrm{M})$ for $24 \mathrm{~h}$ before harvest. Whole cell extracts (WCE) were subjected to immunoprecipitation (IP) and immunoblot assay (IB) using anti-Myc and anti-MEF2C antibodies.

\section{Hesperedin selectively modulates MyoD activity}

We also examined the effect of hesperedin on the activity of myogenin and other MRFs in the promoter activity of myogenin and MCK. Enforced myogenin expression activated its own promoter activity, but hesperedin did not further increase the transcriptional activity of myogenin (Figure 4A). While MEF2C expression had no significant effect on myogenin promoter activity, its co-expression with MyoD cooperatively increased myogenin promoter activity induced by MyoD (Figure 4B). Hesperedin amplified MyoD-induced promoter activity, but did not affect the cooperative activity of MyoD and MEF2C (Figure 4B). Moreover, the direct interaction between MEF2C and MyoD was not affected by hesperedin (Figure 4C), indicating specific transcriptional regulation by hesperedin through activation of MyoD, not other transcription factors.

\section{Hesperedin facilitates nuclear expression and DNA binding activity of MyoD}

To elucidate the regulatory mechanisms underlying MyoD activation by hesperedin, we first assessed the subcellular localization of MyoD in the presence of hesperedin. Interest- ingly, hesperedin dose-dependently enhanced nuclear localization of MyoD in C2C12 cells, but did not affect expression of a nuclear control protein, OCT1, as shown by immunoblotting and densitometric scanning (Figure 5A) and immunocytochemistry using anti-myogenin antibody (Figure 5B). In addition, the DNA-MyoD binding complex that was specifically inhibited by competitor DNA was increased by treatment with hesperedin (Figure 5C), reflecting the increased nuclear level of MyoD by hesperedin. To explore the direct effect of hesperedin on the association of MyoD with myogenin promoter, a DNA pull-down assay was conducted using whole cell extracts from cells overexpressing MyoD. Hesperedin increased the DNA binding affinity of MyoD but did not directly change MyoD expression levels (Figure 5D). This flavonoid may therefore affect both the nuclear localization and DNA binding activity of MyoD.

\section{The pro-myogenic activity of hesperedin requires MyoD expression}

To confirm that the pro-myogenic activity of hesperedin was not confined to myoblast C2C12 cells, C3H10T1/2 mesenchymal stem cells were treated with hesperedin in the absence or presence of MyoD expression. As MyoD is critical 
$\mathbf{A}$
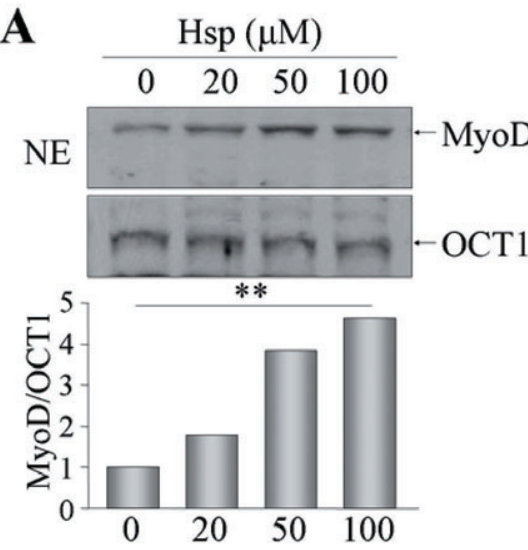

C

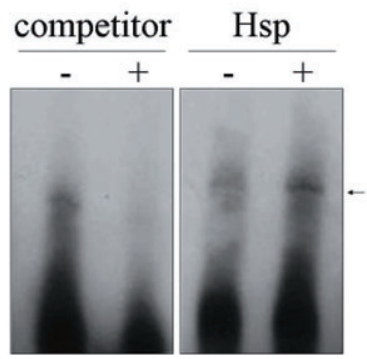

B

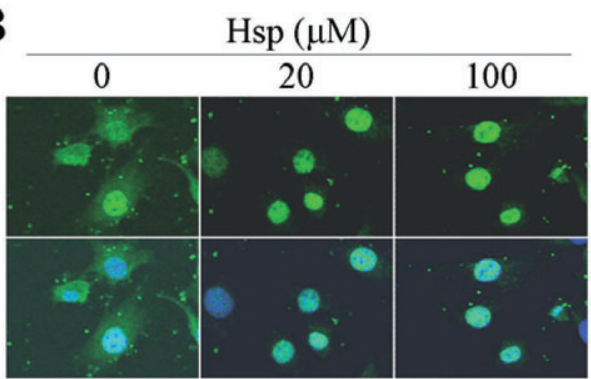

D

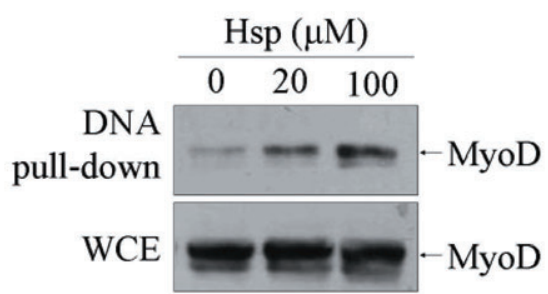

\section{Figure 5}

Increased nuclear expression of MyoD and its DNA binding activity in the presence of hesperedin. (A) C2C12 cells were grown to confluence and treated with hesperedin (Hsp) for $24 \mathrm{~h}$ in low mitogen medium. Nuclear extracts (NE) were harvested and resolved by SDS-PAGE, followed by an immunoblot of MyoD. OCT1 antibody was used as a nuclear protein loading control. The level of MyoD was quantitated by densitometric scanning and normalization to the OCT1 level. ${ }^{* *} P<0.005$. (B) Confluent $\mathrm{C} 2 \mathrm{C} 12$ cells were treated with hesperedin for $24 \mathrm{~h}$ and incubated with anti-MyoD antibody, followed by secondary antibody with fluorescence. Cells were also stained with DAPI and observed at high magnification. (C) Cells were treated with $(+)$ or without $(-)$ hesperedin $(100 \mu \mathrm{M})$ for $24 \mathrm{~h}$. Nuclear extracts were harvested and incubated with MyoD-binding element of myogenin promoter as described in Methods. Nuclear extracts of control cells were incubated with or without a specific competitor MyoD-binding element. (D) 293T cells were transfected with MyoD expression vector and incubated with hesperedin for $24 \mathrm{~h}$. Whole cell extracts were incubated with a biotinylated MyoD-binding element of myogenin gene promoter, and subsequently incubated with streptavidin agarose beads. Precipitates were loaded onto a SDS-PAGE gel and subjected to immunoblot assay using anti-MyoD Ab. MyoD expression in whole cell extracts was analysed as a loading control.

for myogenic conversion of non-muscle cell types (Lassar and Munsterberg, 1994), there was no induction of muscle gene expression by hesperedin in the absence of MyoD (Figure 6A). However, comparable expression of MyoD by viral transduction increased myogenin expression (Figure 6A and B). In addition, hesperedin dose-dependently elevated the gene expression of myogenin and MCK in the presence of MyoD expression (Figure 6C and D). These results strongly suggest that hesperedin has a potent pro-myogenic activity via regulation of MyoD activity in the myogenic differentiation of mesenchymal stem cells.

\section{Hesperedin accelerates muscle regeneration induced by injury in vivo}

We further examined whether hesperedin affects muscle differentiation and regeneration in vivo. Mouse TA muscles were subjected to a freeze injury, followed by i.p. injection of hesperedin, daily for 6 days. Injured muscle exhibited pronounced necrosis and extensive immune cell infiltration with a few regenerating myofibers on day 7 post-injury, whereas treatment with hesperedin $\left(50 \mathrm{mg} \cdot \mathrm{kg}^{-1}\right)$ accelerated the induction of centrally nucleated regenerating myofibers and successfully induced lesion repair in injured muscle (Figure 7A). In addition, myogenin expression was increased in injury-induced regenerating muscle and further enhanced by the hesperedin treatment. The muscle markers in regenerating muscle, desmin and vimentin, were also expressed in regenerating muscle while those expression levels were attenuated in successfully repaired muscle tissues after treatment with hesperedin (Figure 7B). These results indicate that treatment with hesperedin may enhance myogenin expression in muscle regeneration processes and improve injuryinduced muscle differentiation and regeneration in vivo.

\section{Discussion}

In this study, we have identified a pro-myogenic function of hesperedin and its regulatory mechanisms, which include promoting nuclear localization of MyoD and its interaction with target gene promoters, as well as enhancement of 
A

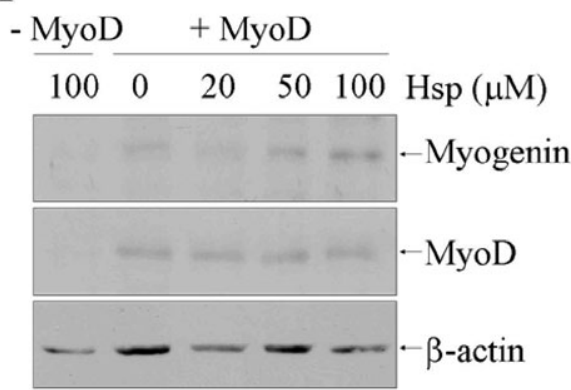

C

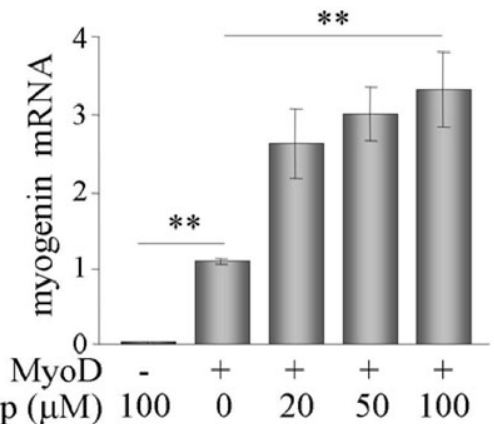

B

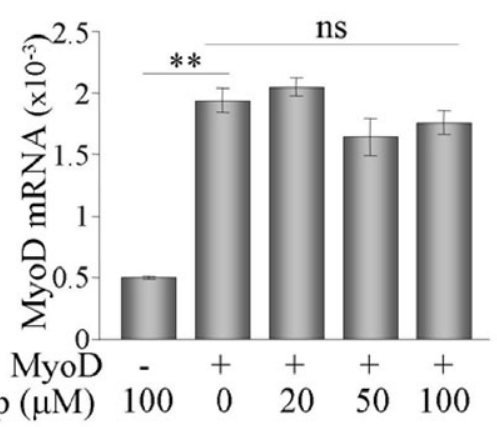

D

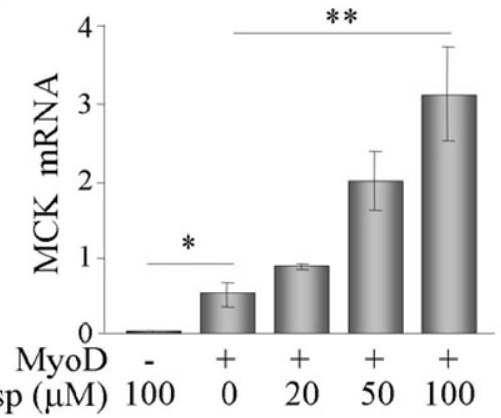

\section{Figure 6}

Stimulatory effect of hesperedin in MyoD-induced transdifferentiation. C3H10T1/2 cells were infected with viral supernatants expressing MyoD $(+\mathrm{MyoD})$ or control (-MyoD) and cell clones were selected in the presence of puromycin. Cells were grown to $100 \%$ confluence and growth medium was replaced with differentiation medium containing different amounts of hesperedin (Hsp). (A) Cell clones were cultured in the presence of hesperedin for 2 days. The expression levels of MyoD, myogenin and $\beta$-actin were determined by immunoblot assay. (B-D) Cells were cultured under differentiation conditions with hesperedin for 2 days. Total RNA was prepared from the cells and subjected to real-time PCR analysis. Relative expression level of MyoD (B), myogenin (C) and MCK (D), normalized to $\beta$-actin levels. ns, not significant; ${ }^{*} P<0.05$; ${ }^{*} P<0.005$.

MyoD-mediated myogenic gene transcription and myogenic differentiation.

MyoD is an essential transcription factor for initiating skeletal muscle differentiation and MyoD deficiency impairs MHC expression (Tapscott et al., 1988; Rudnicki et al., 1993). MyoD associates with other transcription factors such as MEF2C (Zang et al., 2004), pRB (Gu et al., 1993) and E12/ E47-like proteins (Lassar et al., 1991) to activate gene transcription of myogenin and muscle-specific genes by directly binding to gene promoters/enhancers in the nucleus (Polesskaya et al., 2002; Wilson and Rotwein, 2006). Our results reveal that hesperedin increased the nuclear localization of MyoD and the binding affinity of MyoD to the gene promoter, but did not affect the functional cooperation between MyoD and MEF2C. Hesperedin seems to selectively affect MyoD, not MEF2C or myogenin, but its role in the heterodimerization of MyoD with other transcription factors is unclear.

Cell cycle arrest is an important molecular mechanism for inducing cell differentiation. Two molecules controlling cell cycle exit, p21 and p57, modulate skeletal muscle differentiation, and both p21- and p57-deficient cells fail to form myotubes (Zhang et al., 1999c). Cell cycle progression, coupled with cyclin D1-dependent nuclear targeting of CDK4, negatively modulates myocyte differentiation (Zhang et al., 1999a). However, under low-mitogen conditions, MyoD directly interacts with CDK4 and inhibits pRb phosphoryla- tion, resulting in exit from the cell cycle and promotion of myogenic differentiation (Zhang et al., 1999b; Wei and Paterson, 2001). Interestingly, hesperedin inhibits cell proliferation of rat vascular smooth muscle cells, by suppressing $\mathrm{pRb}$ phosphorylation and lowering cyclin D expression (Jin et al., 2008). Collectively, hesperedin activates MyoD expression in the nucleus and attenuates the level of cyclin D and phosphorylated $\mathrm{pRb}$, providing the molecular mechanisms underlying the pro-myogenic effects of hesperedin.

A high dietary intake of hesperedin has been implicated in lowering serum cholesterol and the risk of cardiovascular disease (Bok et al., 1999; Wilcox et al., 2001; Kanaze et al., 2007; Jin et al., 2008; Liu et al., 2008), inhibiting breast cancer (Choi, 2007) and protecting cells from oxidative stresses (Kim et al., 2004; Cho, 2006; Choi and Ahn, 2008). Our results additionally suggest that hesperedin may have a beneficial role in promoting muscle cell differentiation and regeneration after muscle injury in vivo. Muscle injuries, which can be caused by a variety of genetic and environmental factors such as surgery, cancer, inflammation, infections and oxidative stresses, undergo various phases during healing such as myofiber degeneration, inflammation, regeneration and fibrosis at injured sites (Huard et al., 2002; Charge et al., 2004; Grefte et al., 2007; Ten Broek et al., 2010). During myoblast differentiation or regeneration, MyoD is essential for skeletal muscle repair of damaged tissue (Ferrari et al., 1998; Cooper et al., 1999; Charge et al., 2004). Hesperedin administration 
A

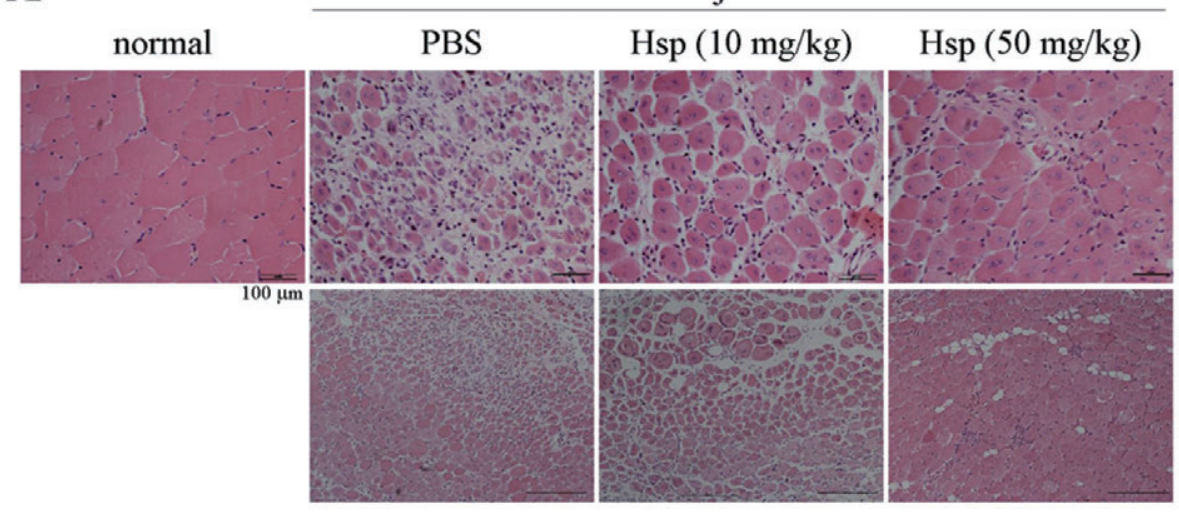

B injured

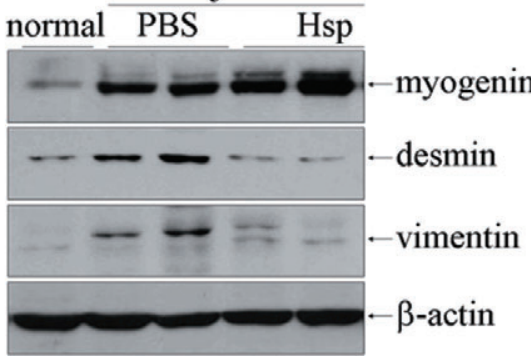

\section{Figure 7}

In vivo muscle regeneration enhanced by hesperedin treatment. TA muscles of C57BL6 mice $(n=6)$ were damaged by freeze injury. Mice were intraperitoneally injected with either PBS or hesperedin ( $\mathrm{Hsp} ; 10$ and $50 \mathrm{mg} \cdot \mathrm{kg}^{-1}$, i.p.) every day and killed on day 7 . (A) TA muscles were sectioned and stained with haematoxylin and eosin. Representative images are presented; scale bar indicates $100 \mu \mathrm{m}$. (B) Whole cell extracts were harvested from TA muscles and resolved by SDS-PAGE with subsequent immunoblotting with antibodies against myogenin, vimentin, desmin or $\beta$-actin.

may activate $\mathrm{MyoD}$ to induce gene transcription of the muscle genes myogenin and MCK.

In conclusion, the ability of the dietary flavonoid, hesperedin, to activate MyoD and subsequent myogenin expression and to promote muscle differentiation and regeneration may indicate beneficial therapeutic potential for recovery from athletic injury and treating muscle diseases, including myopathy and muscular dystrophy.

\section{Acknowledgements}

We thank Dr Andrew B. Lassar for generous gifts of MCK-Luc, myogenin-Luc, MyoD and myogenin expression plasmids. This work was supported by basic research program (20090073324, ESH) and Mid-career Researcher Program (20090084879, ESH and JHH) through NRF grants funded by the MEST and partly by the NCRC program (R15-2006-020).

\section{Conflict of interest}

The authors declare that they have no conflict of interest.

\section{References}

Ameer B, Weintraub RA, Johnson JV, Yost RA, Rouseff RL (1996). Flavanone absorption after naringin, hesperidin, and citrus administration. Clin Pharmacol Ther 60: 34-40.

Amin A, Buratovich M (2007). The anti-cancer charm of flavonoids: a cup-of-tea will do! Recent Pat Anticancer Drug Discov 2: 109-117.

Berkes CA, Tapscott SJ (2005). MyoD and the transcriptional control of myogenesis. Semin Cell Dev Biol 16: 585-595.

Bi W, Deng JM, Zhang Z, Behringer RR, de Crombrugghe B (1999). Sox9 is required for cartilage formation. Nat Genet 22: 85-89.

Bok SH, Lee SH, Park YB, Bae KH, Son KH, Jeong TS et al. (1999). Plasma and hepatic cholesterol and hepatic activities of 3-hydroxy-3-methyl-glutaryl-CoA reductase and acyl CoA: cholesterol transferase are lower in rats fed citrus peel extract or a mixture of citrus bioflavonoids. J Nutr 129: 1182-1185.

Borradaile NM, Carroll KK, Kurowska EM (1999). Regulation of HepG2 cell apolipoprotein B metabolism by the citrus flavanones hesperedin and naringenin. Lipids 34: 591-598.

Borradaile NM, de Dreu LE, Barrett PH, Behrsin CD, Huff MW (2003). Hepatocyte apoB-containing lipoprotein secretion is decreased by the grapefruit flavonoid, naringenin, via inhibition of MTP-mediated microsomal triglyceride accumulation. Biochemistry 42: $1283-1291$. 
Cazarolli LH, Zanatta L, Alberton EH, Figueiredo MS, Folador P, Damazio RG et al. (2008). Flavonoids: prospective drug candidates. Mini Rev Med Chem 8: 1429-1440.

Charge SB, Rudnicki MA (2004). Cellular and molecular regulation of muscle regeneration. Physiol Rev 84: 209-238.

Cho J (2006). Antioxidant and neuroprotective effects of hesperidin and its aglycone hesperedin. Arch Pharm Res 29: 699-706.

Choi EJ (2007). Hesperedin induced G1-phase cell cycle arrest in human breast cancer MCF-7 cells: involvement of CDK4 and p21. Nutr Cancer 59: 115-119.

Choi EJ, Ahn WS (2008). Neuroprotective effects of chronic hesperedin administration in mice. Arch Pharm Res 31: 1457-1462.

Choi EM, Kim YH (2008). Hesperedin attenuates the highly reducing sugar-triggered inhibition of osteoblast differentiation. Cell Biol Toxicol 24: 225-231.

Cooper RN, Tajbakhsh S, Mouly V, Cossu G, Buckingham M, Butler-Browne GS (1999). In vivo satellite cell activation via Myf5 and MyoD in regenerating mouse skeletal muscle. J Cell Sci 112: 2895-2901.

Davis RL, Weintraub H, Lassar AB (1987). Expression of a single transfected cDNA converts fibroblasts to myoblasts. Cell 51: 987-1000.

Ferrari G, Cusella-De Angelis G, Coletta M, Paolucci E, Stornaiuolo A, Cossu G et al. (1998). Muscle regeneration by bone marrow-derived myogenic progenitors. Science 279: 1528-1530.

Grefte S, Kuijpers-Jagtman AM, Torensma R, Von den Hoff JW (2007). Skeletal muscle development and regeneration. Stem Cells Dev 16: 857-868.

Gregory CA, Ylostalo J, Prockop DJ (2005). Adult bone marrow stem/progenitor cells (MSCs) are preconditioned by microenvironmental 'niches' in culture: a two-stage hypothesis for regulation of MSC fate. Sci STKE 2005:294: pe37.

Gu W, Schneider JW, Condorelli G, Kaushal S, Mahdavi V, Nadal-Ginard B (1993). Interaction of myogenic factors and the retinoblastoma protein mediates muscle cell commitment and differentiation. Cell 72: 309-324.

Harada S, Rodan GA (2003). Control of osteoblast function and regulation of bone mass. Nature 423: 349-355.

Hasty P, Bradley A, Morris JH, Edmondson DG, Venuti JM, Olson EN et al. (1993). Muscle deficiency and neonatal death in mice with a targeted mutation in the myogenin gene. Nature 364: 501-506.

Hirata A, Murakami Y, Shoji M, Kadoma Y, Fujisawa S (2005). Kinetics of radical-scavenging activity of hesperedin and hesperidin and their inhibitory activity on COX-2 expression. Anticancer Res 25: 3367-3374.

Huang Y, Tsang SY, Yao X, Chen ZY (2005). Biological properties of baicalein in cardiovascular system. Curr Drug Targets Cardiovasc Haematol Disord 5: 177-184.

Huard J, Li Y, Fu FH (2002). Muscle injuries and repair: current trends in research. J Bone Joint Surg Am 84-A: 822-832.

Jeong H, Bae S, An SY, Byun MR, Hwang JH, Yaffe MB et al. (2010). TAZ as a novel enhancer of MyoD-mediated myogenic differentiation. FASEB J 24: 3310-3320.

Jin YR, Han XH, Zhang YH, Lee JJ, Lim Y, Kim TJ et al. (2008), Hesperedin, a bioflavonoid, inhibits rat aortic vascular smooth muscle cells proliferation by arresting cell cycle. J Cell Biochem 104: $1-14$
Jung H, Lee MS, Jang EJ, Ahn JH, Kang NS, Yoo SE et al. (2009). Augmentation of PPARgamma-TAZ interaction contributes to the anti-adipogenic activity of KR62980. Biochem Pharmacol 78: 1323-1329.

Kanaze FI, Bounartzi MI, Georgarakis M, Niopas I (2007). Pharmacokinetics of the citrus flavanone aglycones hesperedin and naringenin after single oral administration in human subjects. Eur J Clin Nutr 61: 472-477.

Kim JY, Jung KJ, Choi JS, Chung HY (2004). Hesperedin: a potent antioxidant against peroxynitrite. Free Radic Res 38: 761-769.

Komori T, Yagi H, Nomura S, Yamaguchi A, Sasaki K, Deguchi K et al. (1997). Targeted disruption of Cbfa1 results in a complete lack of bone formation owing to maturational arrest of osteoblasts. Cell 89: 755-764.

Lassar A, Munsterberg A (1994). Wiring diagrams: regulatory circuits and the control of skeletal myogenesis. Curr Opin Cell Biol 6: $432-442$.

Lassar AB, Davis RL, Wright WE, Kadesch T, Murre C, Voronova A et al. (1991). Functional activity of myogenic HLH proteins requires hetero-oligomerization with E12/E47-like proteins in vivo. Cell 66: 305-315.

Lassar AB, Skapek SX, Novitch B (1994). Regulatory mechanisms that coordinate skeletal muscle differentiation and cell cycle withdrawal. Curr Opin Cell Biol 6: 788-794.

Lee NK, Choi SH, Park SH, Park EK, Kim DH (2004). Antiallergic activity of hesperidin is activated by intestinal microflora. Pharmacology 71: 174-180.

Liu L, Shan S, Zhang K, Ning ZQ, Lu XP, Cheng YY (2008). Naringenin and hesperedin, two flavonoids derived from Citrus aurantium up-regulate transcription of adiponectin. Phytother Res 22: $1400-1403$

Molkentin JD, Olson EN (1996). Combinatorial control of muscle development by basic helix-loop-helix and MADS-box transcription factors. Proc Natl Acad Sci USA 93: 9366-9373.

Nabeshima Y, Hanaoka K, Hayasaka M, Esumi E, Li S, Nonaka I et al. (1993). Myogenin gene disruption results in perinatal lethality because of severe muscle defect. Nature 364: 532-535.

Polesskaya A, Rudnicki MA (2002). A MyoD-dependent differentiation checkpoint: ensuring genome integrity. Dev Cell 3: 757-758.

Rudnicki MA, Schnegelsberg PN, Stead RH, Braun T, Arnold HH, Jaenisch R (1993). MyoD or Myf-5 is required for the formation of skeletal muscle. Cell 75: 1351-1359.

Tapscott SJ, Davis RL, Thayer MJ, Cheng PF, Weintraub H, Lassar AB (1988). MyoD1: a nuclear phosphoprotein requiring a Myc homology region to convert fibroblasts to myoblasts. Science 242: 405-411.

Ten Broek RW, Grefte S, Von den Hoff JW (2010). Regulatory factors and cell populations involved in skeletal muscle regeneration. J Cell Physiol 224: 7-16.

Tontonoz P, Hu E, Spiegelman BM (1994). Stimulation of adipogenesis in fibroblasts by PPAR gamma 2, a lipid-activated transcription factor. Cell 79: 1147-1156.

Trzeciakiewicz A, Habauzit V, Mercier S, Barron D, Urpi-Sarda M, Manach C et al. (2010a). Molecular mechanism of hesperedin-7-O-glucuronide, the main circulating metabolite of hesperidin, involved in osteoblast differentiation. J Agric Food Chem 58: 668-675. 
Trzeciakiewicz A, Habauzit V, Mercier S, Lebecque P, Davicco MJ, Coxam V et al. (2010b). Hesperedin stimulates differentiation of primary rat osteoblasts involving the BMP signalling pathway.

J Nutr Biochem 21: 424-431.

Viuda-Martos M, Ruiz-Navajas Y, Fernandez-Lopez J, Perez-Alvarez JA (2008). Functional properties of honey, propolis, and royal jelly. J Food Sci 73: R117-R124.

Wei Q, Paterson BM (2001). Regulation of MyoD function in the dividing myoblast. FEBS Lett 490: 171-178.

Wilcox LJ, Borradaile NM, de Dreu LE, Huff MW (2001). Secretion of hepatocyte apoB is inhibited by the flavonoids, naringenin and hesperedin, via reduced activity and expression of ACAT2 and MTP. J Lipid Res 42: 725-734.

Wilson EM, Rotwein P (2006). Control of MyoD function during initiation of muscle differentiation by an autocrine signaling pathway activated by insulin-like growth factor-II. J Biol Chem 281: 29962-29971.
Yaffe D, Saxel O (1977). A myogenic cell line with altered serum requirements for differentiation. Differentiation 7: 159-166.

Zhang JM, Wei Q, Zhao X, Paterson BM (1999a). Coupling of the cell cycle and myogenesis through the cyclin D1dependent interaction of MyoD with cdk4. EMBO J 18: 926-933.

Zhang JM, Zhao X, Wei Q, Paterson BM (1999b). Direct inhibition of G(1) cdk kinase activity by MyoD promotes myoblast cell cycle withdrawal and terminal differentiation. ЕMBO J 18: $6983-$ 6993.

Zang MX, Li Y, Xue LX, Jia HT, Jing H (2004). Cooperative activation of atrial naturetic peptide promoter by dHAND and MEF2C. J Cell Biochem 93: 1255-1266.

Zhang P, Wong C, Liu D, Finegold M, Harper JW, Elledge SJ (1999c). p21(CIP1) and p57(KIP2) control muscle differentiation at the myogenin step. Genes Dev 13 213-224. 